\title{
An Exceptional Case of Bilateral Radiocarpal Dislocation with Fracture of the Radial Styloid Associated to a Tiered Trauma of the Upperlimb
}

\author{
Hamza Benameur*, Mohamed Fahsi, Marwane Abouchane, Ahmed Reda Haddoun, \\ Mohamed Nechad \\ Department of Orthopaedic Surgery, Ibn Rochd Hospital, Casablanca, Morocco \\ Email: ${ }^{*}$ Hamza.benameur@gmail.com, fahsiabdo@gmail.com, abouchane123@gmail.com, \\ a.hdoun@hotmail.com, M.nechad@hotmail.com
}

Received 23 September 2015; accepted 12 October 2015; published 15 October 2015

Copyright (C) 2015 by authors and OALib.

This work is licensed under the Creative Commons Attribution International License (CC BY). http://creativecommons.org/licenses/by/4.0/

(c) (i) Open Access

\begin{abstract}
Radiocarpal dislocation is a particular entity, infrequent, representing only $0.2 \%$ of all dislocationsas evidenced by the scarcity of publications, which mainly affects young patients, and most often the result of violent trauma. We reported a case of a 35-year-old male patient who sustained dorsal radiocarpal dislocation after a fall from a high place, with fracture of the radial and ulnar styloid process in both wrists, associated to a tiered trauma of the right upperlimb. He was treated with closed reduction and immobilized by cast for the bilateral radiocarpal dislocation, and treated surgically for the tiered trauma of the upperlimb. The evaluation at 3 months showed favorable results. This case is one of the few similar cases reported because it is an uncommon pathology and it is even less frequent because the injury involves both wrists and the upperlimb.
\end{abstract}

Keywords

Hand, Radiocarpal, Dislocation, Fracture, Triered Trauma

Subject Areas: Orthopedics

\section{Introduction}

Radiocarpal dislocations are defined as a loss of total and permanent contact between the lower part of the two

${ }^{*}$ Corresponding author.

How to cite this paper: Benameur, H., Fahsi, M., Abouchane, M., Haddoun, A.R. and Nechad, M. (2015) An Exceptional Case of Bilateral Radiocarpal Dislocation with Fracture of the Radial Styloid Associated to a Tiered Trauma of the Upperlimb. Open Access Library Journal, 2: e1992. http://dx.doi.org/10.4236/oalib.1101992 
bones of the forearm and the carpal articular surface.

This is a particular entity, infrequent, representing only $0.2 \%$ [1] of all dislocations as evidenced by the scarcity of publications, which mainly affects young patients, and most often the result of violent trauma.

The treatment of radiocarpal dislocation was variable in the literature; some authors conclude to the superiority of surgical treatment, others have obtained very good results through orthopedic treatment [2].

On the other hand, the management and monitoring being particularly heavy and extended over time, it is not always easy to evaluate the functional results and judge the effectiveness or otherwise of the therapeutic strategy. Only one case of this type of injury was reported [3].

Our work will focus on an exceptional case of a 35-year-old male, who fell from a high place, causing pain, functional disability and a "dinner fork" deformity of both wrists, associated to pain, functional disability and deformity of the right elbow, in whom radiological assessment revealed a bilateral radiocarpal dislocation associated with a tiered trauma of the upper limb.

The aim, according to the analysis of our results and the literature review:

$>$ To study the impact of associations lesion on upper limb function.

$>$ Discuss the different therapeutic modalities for the prevention of lesion associated complications.

\section{Clinical Case}

This is a male, 35 year-old patient, builder, without any remarkable medical history who fell from a high place and applied an excessive load to his wrists, which were in extension. He had deformity of both wrists, severe pain and functional disability. Associated to severe pain and functional disability of the right elbow. The initial physical exam found a "dinner fork" deformity in both wrists, increased temperature, severe pain and functional disability. Deformity of the right elbow with ecchymosis. Antero-posterior and lateral wrist X-rays of the wrists and right elbow were taken, which showed dorsal radiocarpal dislocation and fracture of the radial and ulnar styloid process in both wrists (Figure 1 and Figure 2). Dislocation of the right elbow with complex fracture of the radial head and ulnar shaft of the same right upper limb (Figure 3).

In the operating room, Under balanced general anesthesia, closed reduction with external maneuvers were made for both wrists dislocations. Controlled by fluoroscopy, The local temperature and color conditions improved and then an orthopedic treatment was made with cast immobilization for both wrists seeing the stability of the reduction (Figure 4 and Figure 5). Surgical treatment of the elbow before reduction of its dislocation with mini plate for the radial head and a plate of the ulnar shaft (Figure 6).

The casts were removed at 6 weeks. The patient began a physical therapy and rehabilitation program to improve the ranges of motion. Twelve weeks later, the patient has functional ranges of motion and few pain. He resumed his daily activities with few restrictions (Figure 7).

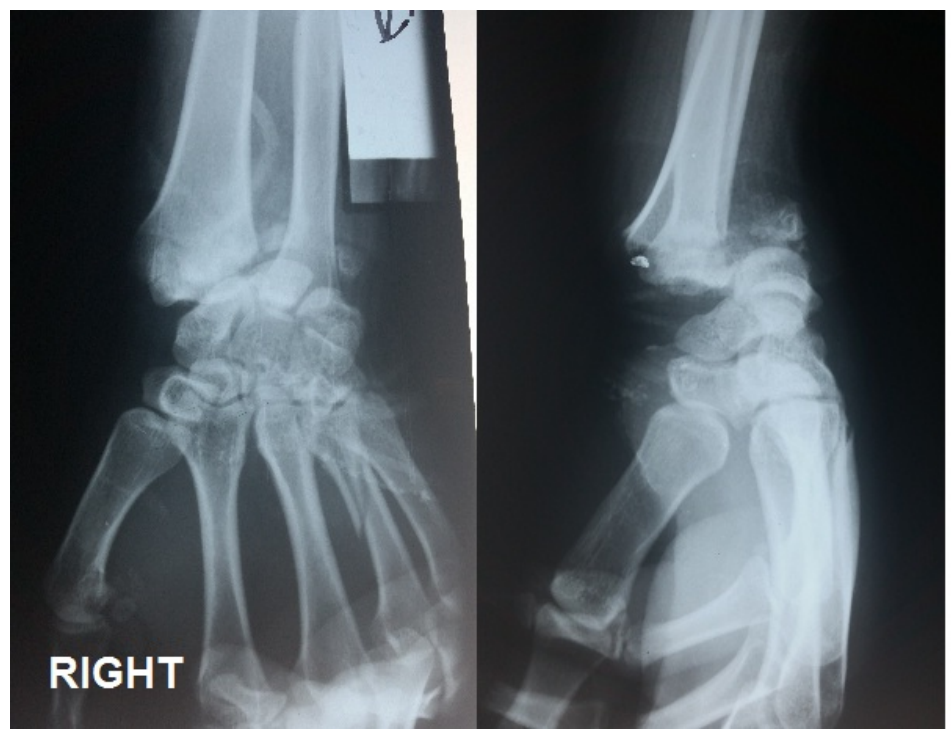

Figure 1. Right wrist before treatment. 


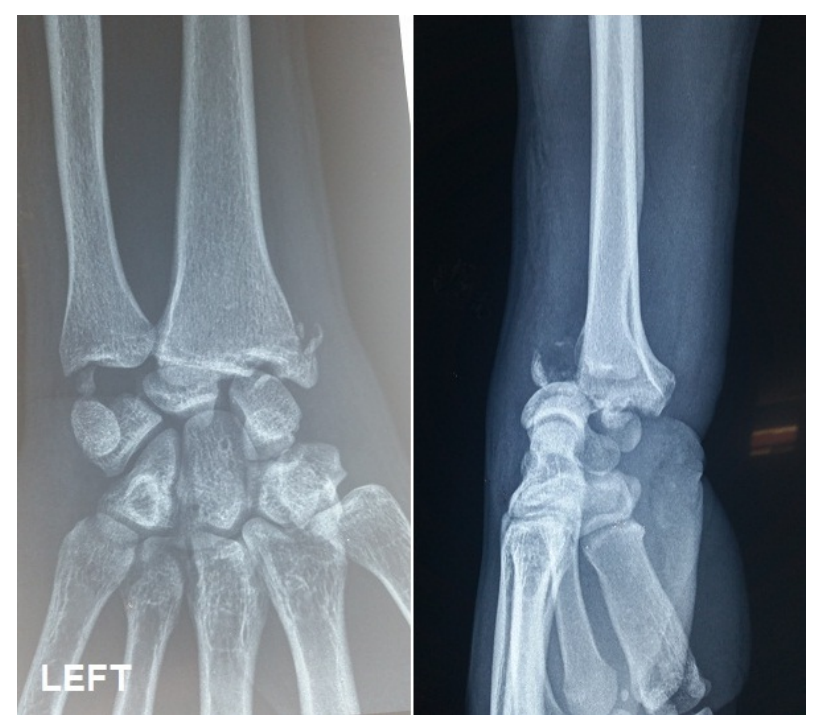

Figure 2. Left wrist before treatment.

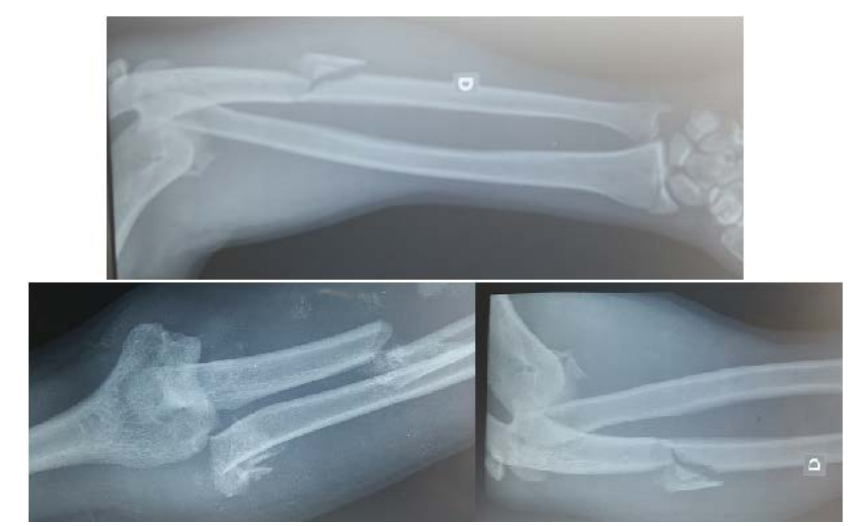

Figure 3. Right elbow before treatment.

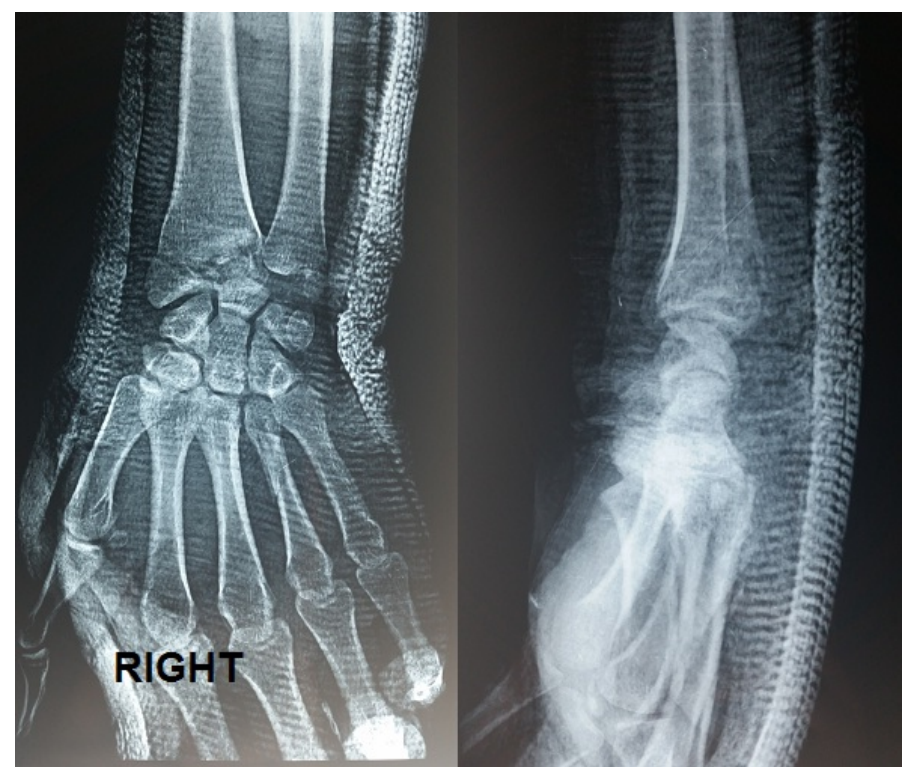

Figure 4. Right wrist after treatment. 


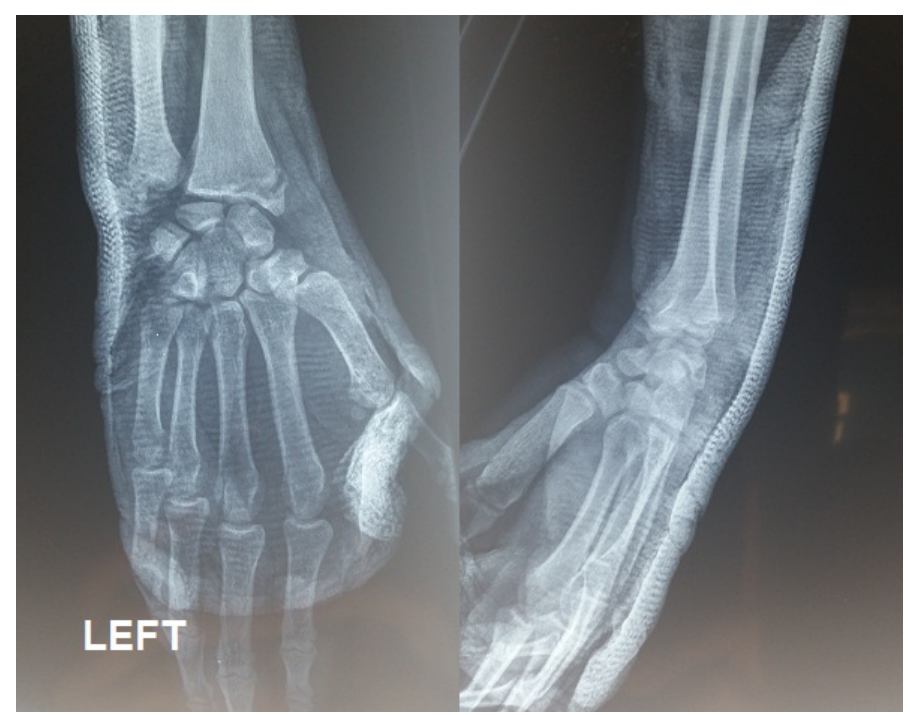

Figure 5. Left wrist after treatment.

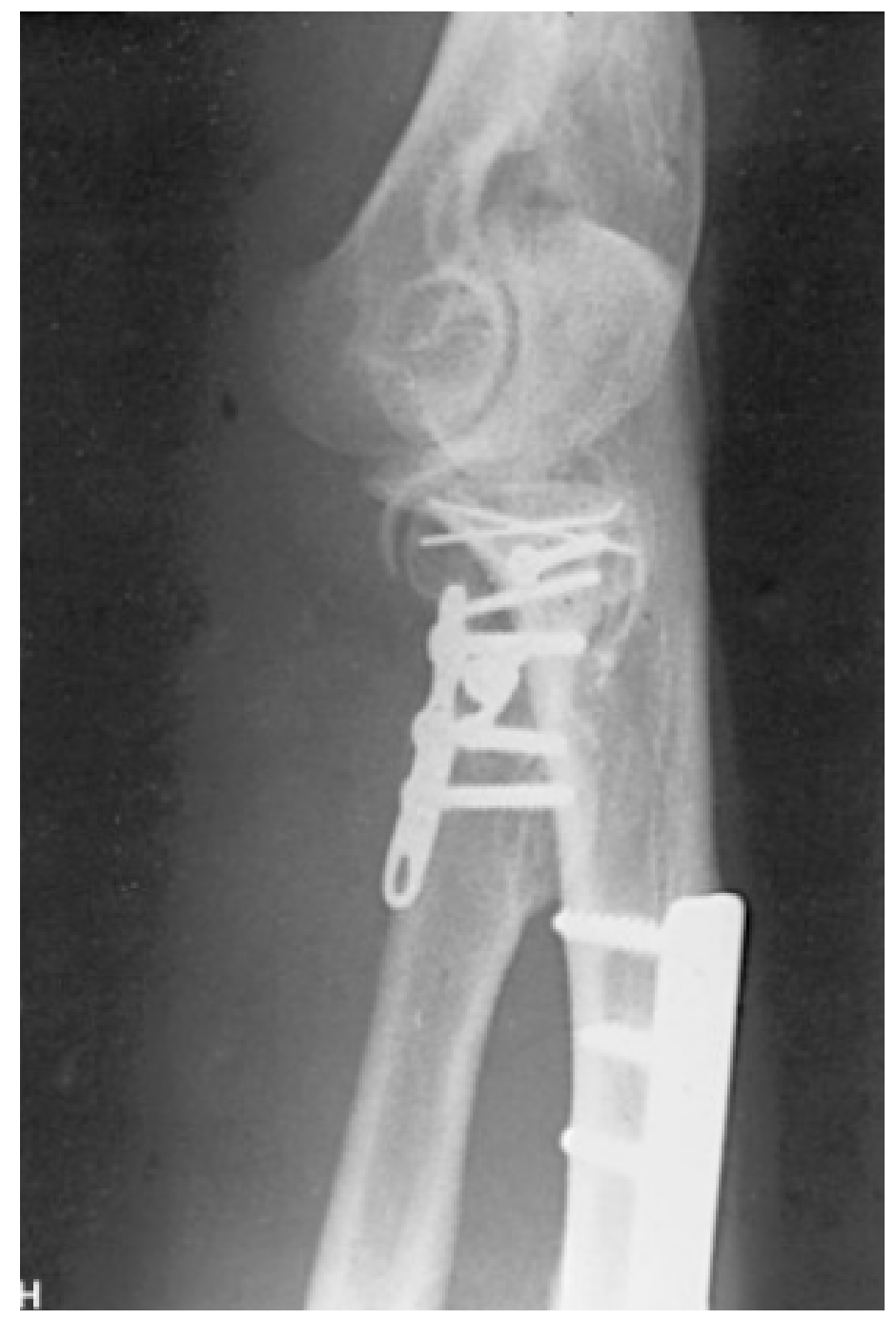

Figure 6. Right elbow after treatment. 

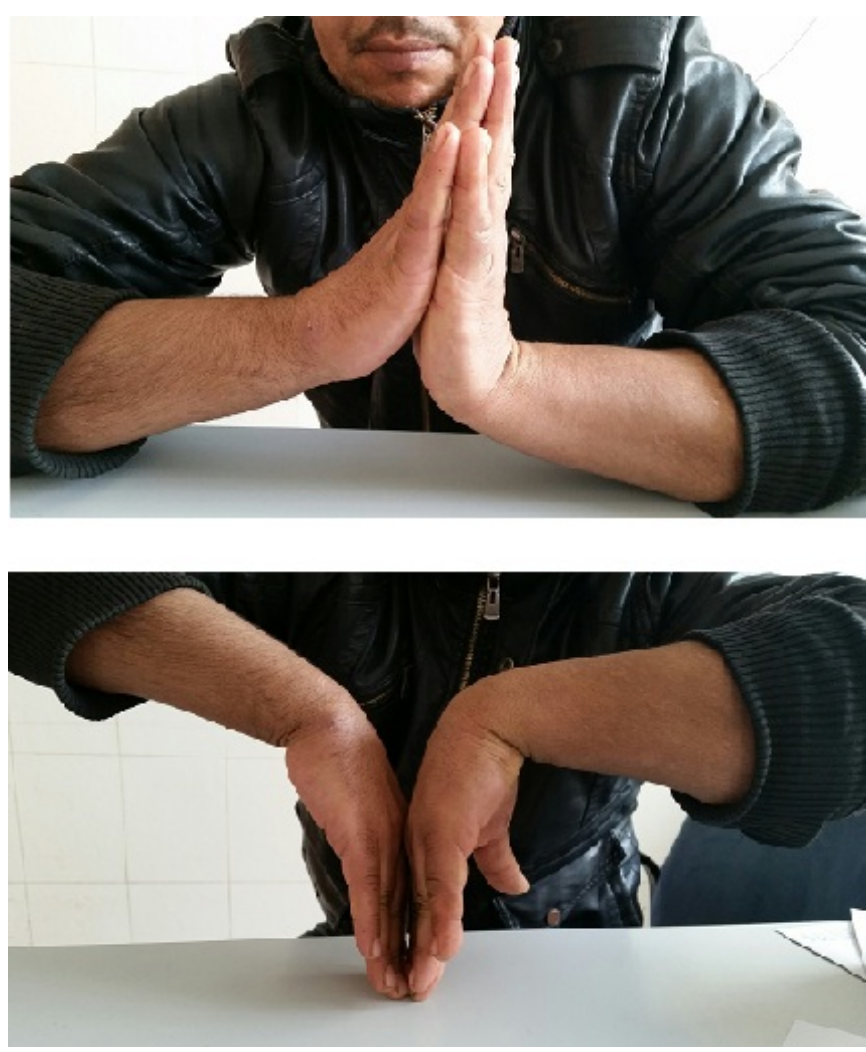

Figure 7. Clinical exam after twelve weeks.

\section{Discussion}

Only one case was reported by Orozco and al [3] of bilateral radiocarpal dislocation. No other cases that associate a bilateral radiocarpal dislocation with multifocal fractures of a same upper limb. Pure dislocations as well as fracture dislocations are almost always the result of high-energy traumatic events which associated extension, pronation and radial inclination [4] but often the patient does not know what the exact mechanism of injury was [5]. Usually dislocations are dorsoulnar, as in the case described herein [3]. The type of dislocation depends on the position of the wrist at the time of the injury [6], There are several anatomo radiological entities, the most common is the posterior fracture-dislocation radiocarpal combining posterior dislocation of the carpus, a fracture of the radial styloid, a marginal tear of the posterior lip of the radial epiphysis and inconstant ulnar styloid; other forms (pure radiocarpal dislocations and luxations-previous radiocarpal fractures) are exceptional.

The therapeutic indications are controversial but most surgeons agree on the first reduction and restoration of the bony anatomy. Some authors routinely operate all fractures radiocarpaldislocations. Others advocate surgical treatment for chess reduction and lesions intra-carpal [3]. In our case, we opted for orthopedic treatment for both wirsts. The wrist is immobilized in flexion or extension, according to the dislocation. Most of the time a cast is used for immobilization purposes; in this case the immobilization was for 6 weeks.

This type of injuries may occur together with intercarpal injuries (type 2 Moneim). The case we present herein only had injury of the radiocarpal joint (type 1Moneim) with fracture of the ulnar and radial styloid. surgical fixation of lesions is a topic of discussion [2] our attitude was the orthopedic treatment as recommended Moneim for type 1 [2]. In none of the reports reviewed were there any ulnarstyloid process fractures. We provided conservative treatment.

\section{Conclusions}

The radiocarpal dislocation is a rare and traumatic damage occuring after violent trauma which explains the frequency of lesions on both the wrist and other bone segments through multiple trauma. Always stabilize intracarpiennes injuries and distal radius-ulna dislocation. 
Whatever orthopedic or surgical treatment, anatomical reduction in urgency and good joint congruence with effective restraint are the guarantee of a good result.

The major risk is evolving radiocarpal osteoarthritis, hence the importance of a good emergency surgery.

\section{Conflicts of Interest}

The authors declare no conflict of interest.

\section{Contributions of Authors}

All authors read and approved this manuscript.

The patient approved the case report.

\section{References}

[1] Dunn, E.W. (1972) Fractures and Dislocations of the Carpus. Surgical Clinics of North America, 52, 1513.

[2] Dahmani, O., et al. (2013) Radiocarpal Dislocation (About Nine Cases). Fes, Morocco, de la Main, 32, 30-36. http://dx.doi.org/10.1016/j.main.2012.12.005

[3] Orozco, V. and Orozco, A. (2010) Radiocarpal Dislocation (About Nine Cases). Acta Ortopédica Mexicana, 24, 408410.

[4] Lahrach, K., et al. (2014) Radiocarpal Fractures Dislocations: Ten Cases and Review of the Literature. Journal de Traumatologie du Sport, 31, 133-136. http://dx.doi.org/10.1016/j.jts.2014.07.005

[5] Bucholz, R.W. and Hechman, J.D. (2003) Fracturas en el adulto. Rockwood and Greens. Quinta Edición. Madrid España, Marbán Libros SL, 2, 749-766.

[6] Gomar, F. (1980) Traumatología. Miembro Superior. Valencia, 1441-1471. 